\title{
UNIVERSITYOF
}

FORWARD

THINKING

WESTMINSTER用

WestminsterResearch

http://www.westminster.ac.uk/westminsterresearch

\section{Agent-Based Simulation of the Evolution of Enterprise Carbon} Assets

Zeng, Y., Yin and Li, Shuliang

This is a copy of the author's accepted version of a paper subsequently published in the proceedings of the International Conference on Robots \& Intelligent Systems (ICRIS2016), Zhangjiajie, China, 27 to 28 Aug 2016, IEEE.

It is available online at:

https://dx.doi.org/10.1109/ICRIS.2016.16

(C) 2016 IEEE . Personal use of this material is permitted. Permission from IEEE must be obtained for all other uses, in any current or future media, including reprinting/republishing this material for advertising or promotional purposes, creating new collective works, for resale or redistribution to servers or lists, or reuse of any copyrighted component of this work in other works.

The WestminsterResearch online digital archive at the University of Westminster aims to make the research output of the University available to a wider audience. Copyright and Moral Rights remain with the authors and/or copyright owners.

Whilst further distribution of specific materials from within this archive is forbidden, you may freely distribute the URL of WestminsterResearch: ((http://westminsterresearch.wmin.ac.uk/)).

In case of abuse or copyright appearing without permission e-mail repository@westminster.ac.uk 
Yin Zeng \& Shuliang Li, “Agent-Based Simulation of the Evolution of Enterprise Carbon Assets”, Proceedings of 2016 International Conference on Robots \& Intelligent Systems, 27th-28th August 2016, Zhangjiajie, China. IEEE.pp.81-84. ISBN 978-1-5090-4155-8/16.

\title{
Agent-Based Simulation of the Evolution of Enterprise Carbon Assets
}

\author{
Yin Zeng ${ }^{1}$, Shuliang $\mathrm{Li}^{2,1}$ \\ ${ }^{1}$ School of Economics \& Management, Southwest Jiaotong University, Chengdu 610031, China \\ zengyin@live.cn \\ ${ }^{2}$ Westminster Business School, University of Westminster, London NW1 5LS, United Kingdom \\ lish@westminster.ac.uk
}

\begin{abstract}
Carbon assets have the value of carbon emission reduction in enterprises and are closely relevant to business images and competitiveness. In this paper, the connotation of carbon assets is clarified. The definition of carbon assets in enterprise business contexts are also provided. In addition, an interactive evolution framework is established to demonstrate the emergent property of carbon assets using multi-agentbased simulation, which can bring a new perspective for enterprises to manage their carbon assets and improve lowcarbon competitiveness.
\end{abstract}

Keywords- Carbon Dioxide Emission; Enterprise Carbon assets; Carbon Asset Evolution; Computer Simulation; Software Agent

\section{INTRODUCTION}

Under the huge pressure of global warming, carbon assets with political characteristics and orientation emerged from Kyoto Protocol. With gradual improvements of international carbon trading markets, the qualities of enterprise carbon emission reduction become assets that can be traded globally. Under the regulation of carbon emission reduction, enterprises are both the subjects which should share the responsibility of fighting against global warming, and the beneficiaries in the era of low carbon economy. This is bound to change the traditional order of world economies. Only the practice of regulation and the adjustment of production management strategies to accumulate carbon assets can enterprises obtain or improve their sustainable competitiveness. Studies and research on the evolution of enterprise carbon assets is very rare at present. Our paper aims to explore the evolution rules of enterprise' carbon assets.

\section{THE CONCEPT OF ENTERPRISE CARBON} ASSETS

\section{A. The connotation of enterprise carbon assets}

The trade value of the quantity of carbon emission reduction was first proposed by Marland [1]. With the development of low carbon economy, the connotation of carbon assets is changing and extending. Carbon assets with trade deadlines on quotas or certification can only create direct profit in a certain period, including carbon emission permits for direct transactions, such as approved quotas, Certified Emission Reduction (CER), etc. In addition, carbon assets also include low-carbon technology, advanced production technology, effective management methods, etc. These assets cannot be directly used for transactions, but can help reduce carbon emissions. Carbon assets can bring economic value to enterprises. Therefore, innovation in lowcarbon technology, clean production capacity and the integration in low carbon development strategy are required for enterprises to obtain the quotas and certified emission reduction. Thus, enterprise carbon assets are the sum of the resources with the values of carbon emission reduction, obtained from the implementation of low-carbon technologies and measures.

\section{B. Definition of enterprise carbon assets}

The completion of carbon-reduction target (i.e., national reduction target or voluntary reduction target), updating the equipment and optimizing relevant processes, can help achieve relevant goals. If an enterprise highlights importance to low-carbon development and establishes a low-carbon management system in achieving their goals, the enterprise's unique resource is being created gradually in this process. And the unique resources will evolve into the enterprise's carbon assets. Hence, enterprise carbon assets and overall carbon reduction capability are integrated into this process. The creative values are more important than monetized tradable carbon emission permits.

Low-carbon development is still not well-understood by Chinese enterprises at present. Their business activities still reply on the targets set by government regulations, rather than applying and integrating carbon asset management methods. With the globalization of supply chains and customers in the background of global contexts, Chinese enterprises are faced with tremendous challenges. Through early deployment of low-carbon strategy, enterprises can gain competitive advantage. Sound and timely business activities are essential to the success of enterprises. And carbon assets are contained in these activities. Enterprises need to define their own carbon assets as listed in Table 1. The carbon assets defined in this study are the typical assets for enterprises.

\section{ENTERPRISE CARBON ASSET EVOLUTION AND COMPUTER SIMULATION}

\section{A. The evolution principle for enterprise carbon assets}

1) Low-carbon technology (Low-carbon products) 
Yin Zeng \& Shuliang Li, “ Agent-Based Simulation of the Evolution of Enterprise Carbon Assets”, Proceedings of 2016 International Conference on Robots \& Intelligent Systems, 27th-28th August 2016, Zhangjiajie, China. IEEE.pp.81-84. ISBN 978-1-5090-4155-8/16.

The low-carbon technologies obtained by enterprises can be transformed into various values, such as efficiency improvement, technology transfer, etc. The technology for

Table1. Definition of enterprise carbon assets

\begin{tabular}{c|l}
\hline Carbon Assets & \multicolumn{1}{c}{ Definition } \\
\hline $\begin{array}{c}\text { Low-carbon } \\
\text { technologies } \\
\text { products) }\end{array}$ & $\begin{array}{l}\text { The application of low-carbon } \\
\text { technologies can achieve } \\
\text { specific carbon emission } \\
\text { reduction. }\end{array}$ \\
\hline $\begin{array}{c}\text { The development of carbon sinks } \\
\text { can bring certified emission } \\
\text { reduction which can be used to } \\
\text { take out the emission or trade. }\end{array}$ \\
\hline $\begin{array}{c}\text { Low-carbon } \\
\text { brands }\end{array}$ & $\begin{array}{l}\text { The value of a low-carbon } \\
\text { brand can be effectively } \\
\text { improved with high market } \\
\text { recognition and the favor from } \\
\text { customers. }\end{array}$ \\
\hline $\begin{array}{c}\text { Low-carbon } \\
\text { circulation }\end{array}$ & $\begin{array}{l}\text { Optimize supply chains; } \\
\text { increase the recognition of low- } \\
\text { carbon brands }\end{array}$ \\
\hline $\begin{array}{c}\text { Carbon positive } \\
\text { externalities } \\
\text { (carbon } \\
\text { footprint) }\end{array}$ & $\begin{array}{l}\text { Make a comprehensive decision } \\
\text { based on low-carbon benefits } \\
\text { and carbon positive externalities } \\
\text { according to the development of } \\
\text { low carbon. }\end{array}$ \\
\hline $\begin{array}{l}\text { Increase the recognition of low- } \\
\text { carbon brands by transparency; } \\
\text { and explore carbon reduction } \\
\text { space. }\end{array}$ \\
\hline audit
\end{tabular}

achieving carbon emission reduction has value attribute of carbon assets, and this value can be calculated by the following model [2]:

$$
V_{t}=(M-C) \cdot Y \cdot P
$$

In the model, $\mathrm{M}$ is the industry benchmark for carbon dioxide emissions with a certain low-carbon technology. C denotes the carbon emission level with current technology. $\mathrm{Y}$ stands for the output in a period of probation. $\mathrm{P}$ is the market price for carbon trading.

2) Carbon sinks

Under the framework of Kyoto Protocol, carbon sinks developed by enterprises has a value that can be used to take out emissions or carry on transactions. The development of carbon sinks is the activities from enterprises' practical demands on their carbon emissions. On the other hand, from the market judgment that the carbon sinks has higher value in carbon trading according to market information, such as plants carbon sequestration project, clean development mechanism project, etc. The model for calculating carbon sinks is as follow [3]:

$$
C_{i+1}=C_{i}+G_{i}-W_{i}-L_{i}
$$

In the model, $C_{i}$ is carbon storage of carbon sinks; $G_{i}$ is the increment of carbon sinks; $W_{i}$ is the loss of carbon sequestration; and $L_{i}$ is the decrement of carbon sinks by cutting or reduction.

3) Clean Production Audit

Clean Production Audit (CPA) is required by the law of national energy conservation and emission reduction. It is also the inevitable choice for enterprises' low-carbon development.

Every enterprise has its own corresponding production functions, and the carbon assets values obtained by the application of CPA are contained in the production value. The model of carbon asset value of CPA with the reference of FEEM-RICE model by Bosetti, etc. [4], and the introduction of carbon asset transformation coefficient $E_{c}$ is formulated as:

$$
V_{c}=A \cdot L^{\alpha} \cdot K^{\beta} \cdot E_{c}
$$

In the model, $A$ is the comprehensive technology level of enterprise production; $L$ is the factor of labor force; $K$ is the factor of materials and capital inputs; $\alpha$ and $\beta$ are the output elasticity of labor and the output elasticity of materials and capital respectively. Carbon asset transformation coefficient reflecting the results of carbon reduction in production and business operation is an important factor for enterprises to decide how to reduce carbon emissions in production.

\section{4) Low-carbon circulation}

Material circulation and information circulation exist in each links of production and business operation. More energy efficient circulation system can bring more carbon emission reduction value for enterprises. For the convenience of analysis, the value contribution from lowcarbon circulation turns into the increase or decrease of labor force factors $\mathrm{L}$.

\section{5) Carbon Disclosure (Carbon Footprint)}

Although carbon disclosure (carbon footprint) cannot directly create the value for carbon emissions, the lowcarbon brand influence can be gradually developed by the increase of the transparency of enterprises' carbon emissions through carbon disclosure, in order to improve the efficiency (sales volume) of low- carbon technology and create the value for carbon emissions. In addition, carbon footprint can also help enterprises explore their potential in carbon emission reduction. We use the improvement of technical level of carbon emissions and the comprehensive production technology to describe the contribution of carbon disclosure (carbon footprint). $\Delta_{C}$ is the target of the volume of carbon emission reduction by technology, $\Delta_{A}$ is the target of the improvement of comprehensive production technology.

\section{6) Low-carbon Brands}

Enterprises' low-carbon can be strengthened and consolidated in the process of the development of carbon assets and the value of low-carbon brands can be improved continuously. The influence coefficient of low-carbon brands is the key factor to determine the value of low-carbon brand [5].

$$
\begin{aligned}
& I=a \cdot x_{1}+b \cdot x_{2}+c \cdot x_{3}+d \cdot x_{4}+e \cdot x_{5} \\
& V=\left(\max \left(V_{t}, V_{c}\right)\right)^{\frac{I_{i+1}}{I_{i}}}
\end{aligned}
$$


Yin Zeng \& Shuliang Li, “ Agent-Based Simulation of the Evolution of Enterprise Carbon Assets”, Proceedings of 2016 International Conference on Robots \& Intelligent Systems, 27 $7^{\text {th }}$ 28th August 2016, Zhangjiajie, China. IEEE.pp.81-84. ISBN 978-1-5090-4155-8/16.

In the model, $I$ is the influence coefficient of a lowcarbon brand; $x_{i}(i=1,2, \mathrm{~L}, 5)$ is the index value of a lowcarbon brand of low-carbon technology (low-carbon products), carbon sinks, clean production audit, low-carbon circulation and carbon positive externalities; $a, b, c, d, e$ are the weights of correspondent indexes.

\section{7) Carbon Positive Externalities}

The utility produced by carbon emission reduction in the development of low-carbon, has not turned into the carbon assets with real value. But it has carbon positive externalities. Enterprises can adjust their development schemes according to the volume of carbon positive externalities.

\section{B. Computer Simulation Model}

This study establishes the computer simulation model of the evolution of enterprise carbon assets by using Netlogo simulation platform. This illustrated in figure 1. Netlogo is a multi-agent modeling environment which can simulate the complicated evolution relationships across enterprise carbon assets. The parameters and the visualized system can vary during simulation runs over time. It contributes to the discovery of the development tendency of carbon assets.
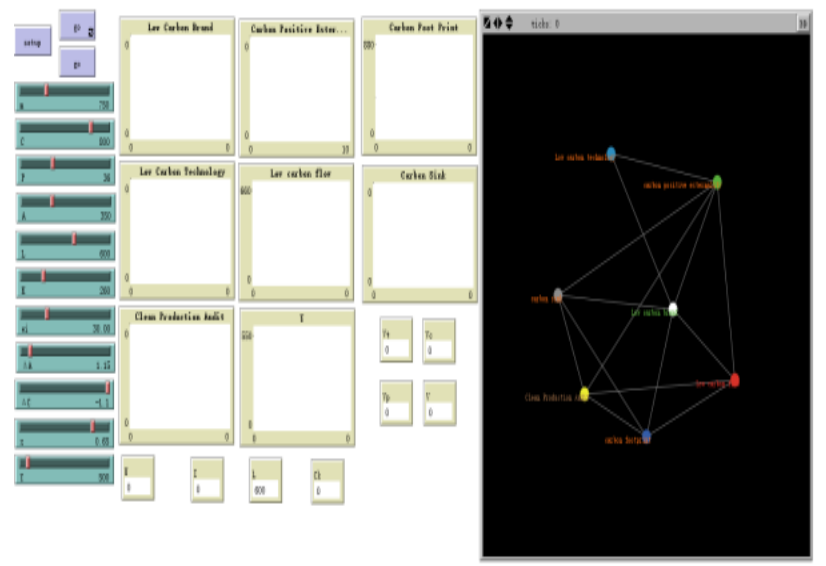

Figure 1. The initial interface of the agent-based simulation of enterprise carbon assets

The study assumes that the low-carbon technology of Chinese domestic enterprise $\mathrm{A}$ is lower than the reduction level of developed country. And enterprise A plans to take low-carbon development. As shown in Table 2, we input the initial values of variables in the multi-agent-based Netlogo simulation platform and run the simulation program of the evolution of carbon assets.

Table 2. The setup instruction of the initial value of

\begin{tabular}{c|c|c}
\multicolumn{3}{|c}{ state variables } \\
\hline Variables & $\begin{array}{c}\text { Initial } \\
\text { value }\end{array}$ & $\begin{array}{c}\text { Adjusting and controlling } \\
\text { patterns }\end{array}$ \\
\hline $\mathrm{M}$ & 750 & Manual control \\
\hline $\mathrm{C}$ & 800 & Simulation decision control \\
\hline $\mathrm{Y}$ & 2500 & Simulation decision control \\
\hline $\mathrm{P}$ & 36 & Manual control \\
\hline
\end{tabular}

\begin{tabular}{c|c|c}
\hline $\mathrm{A}$ & 350 & Simulation decision control \\
\hline $\mathrm{L}$ & 600 & Simulation decision control \\
\hline $\mathrm{K}$ & 260 & Manual control \\
\hline$\Delta \mathrm{A}$ & 1.15 & Simulation decision control \\
\hline$\Delta \mathrm{C}$ & -1.10 & Simulation decision control \\
\hline
\end{tabular}

\section{Simulation results and discussions}

The main rules of the simulation are stated below.

If the comprehensive level of enterprises' technology of carbon emission reduction is lower than the international industry benchmark, then:

(1) Enterprises make efforts to improve the technology of low-carbon reduction;

(2) Before reaching or being not in excess of the international industry benchmark, enterprises will increase input into carbon sinks to offset the over fulfilling volume of carbon emissions;

(3) After meeting or exceeding the international industry benchmark, enterprises will decrease the input of carbon sinks and maintain it at a certain level to respond to emergencies flexibly.

If making improvements on low-carbon technology, then:

(1) Increase the efficiency of labor elements in enterprises' production;

(2) Increase enterprises' comprehensive technology of production.

The simulated experimental results show that the different values of enterprises' carbon assets will increase in varying degrees. This can be seen figure 2 . At the beginning, the value of the low-carbon brand of enterprise A is low because of poor carbon emission reduction and the lack of comparative advantage in the low-carbon technology. Enterprise A adopts more advanced strategy according to the benchmark and decides its $\Delta \mathrm{C}$, the target of the carbon reduction of technology, in each period and optimizes production strategy according to the improvement of technology. 
Yin Zeng \& Shuliang Li, “ Agent-Based Simulation of the Evolution of Enterprise Carbon Assets”, Proceedings of 2016 International Conference on Robots \& Intelligent Systems, 27 $7^{\text {th }}$ 28th August 2016, Zhangjiajie, China. IEEE.pp.81-84. ISBN 978-1-5090-4155-8/16.

Figure 2. Agent-based simulation of the evolutionary process of enterprise A carbon assets

As shown in figures 2 and 3, the experiment simulates 800 time periods and demonstrates that the value of the lowcarbon brand emerges in the middle and keeps a high level in the later stage. The value of other carbon assets can also emerge according to the settings of different circumstances and the adjustment of different development strategies.

Figure 4 indicates that a similar trend towards the efficiency of low carbon circulation as the capacity of an enterprise increases Phased fluctuation shows the adjustment of enterprise's internal circulation efficiency. This is because the improvement of circulation efficiency will affect the original process system. Inefficient circulation equipment and patterns will be abandoned and new technologies and equipment will be introduced to change the way of circulation. This requires a certain period of time for adjustment. An enterprise can propose a specific project to shorten the time scale for adjustment and deliver better value of low-carbon circulation based on the results of simulation and self-condition.

Based on above analyses, it is found that the value contribution from low-carbon circulation and the increase of capacity have positive impact on the improvement of emergent properties of low-carbon brands (see figure 5). Other carbon assets can possess emergent properties by setting up different contexts and associated conditions of an enterprise and adjust low-carbon development strategies. Further work will be discussed in detail in the following research.

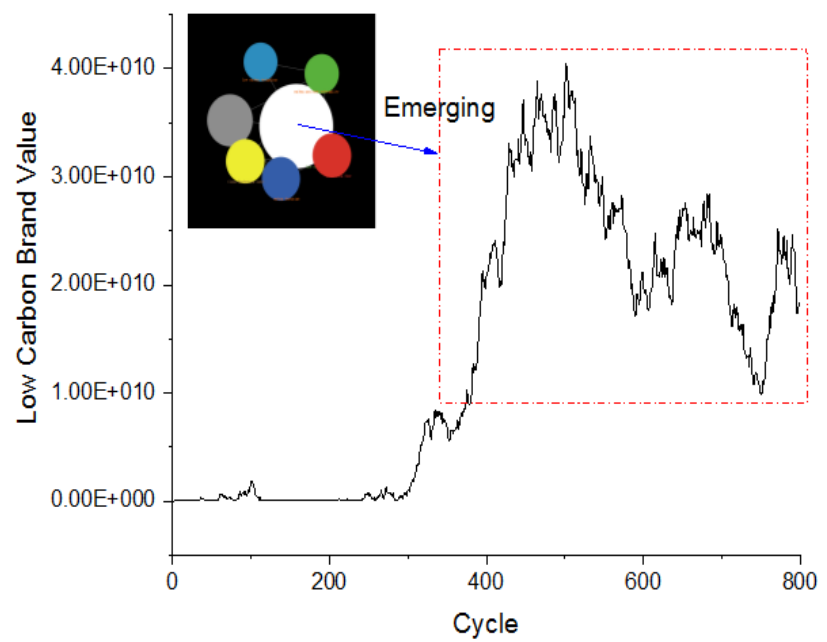

Figure 3. The emergence of the value of the low-carbon brand

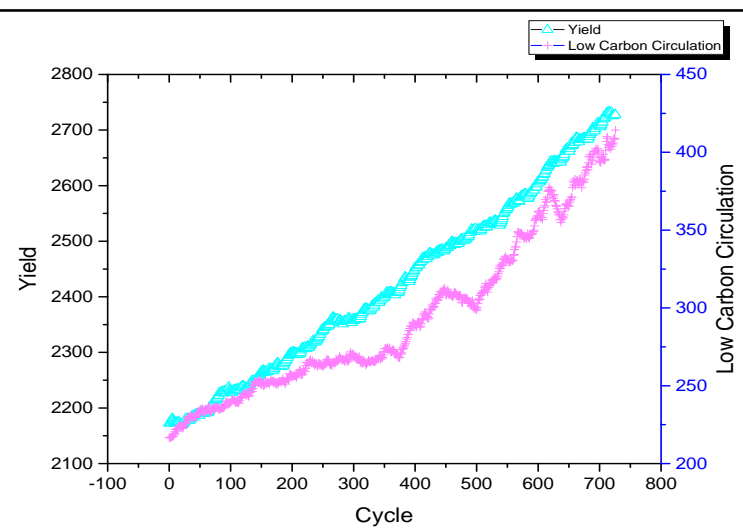

Figure 4. The development trend of output and low-carbon circulation

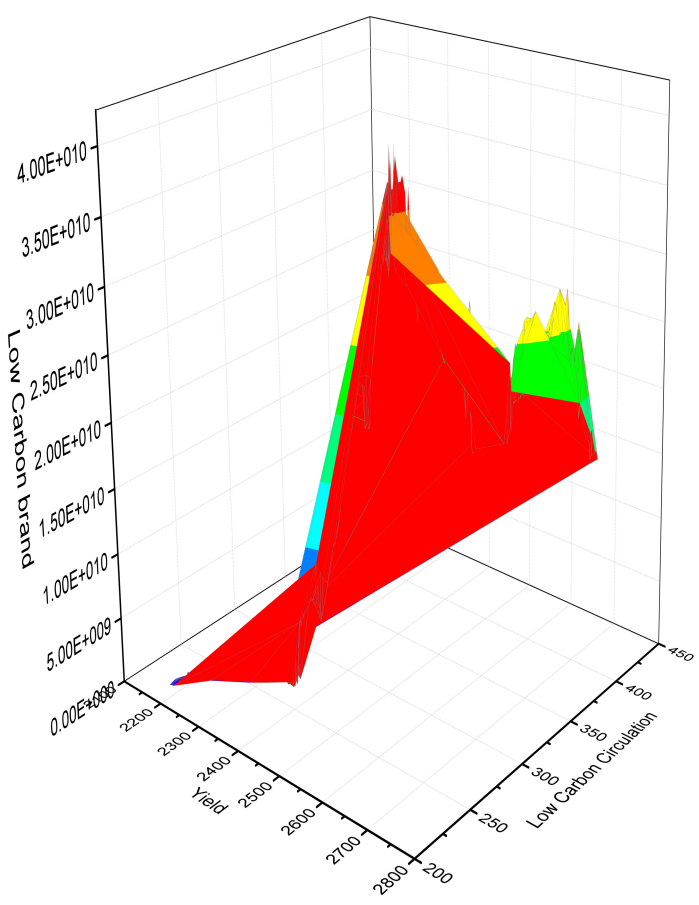

Figure 5. The contribution of emergent property for low-carbon brand from output and low-carbon circulation

\section{IV $\square$ CONCLUSIONS}

In this paper, we have defined seven types of main carbon assets in business highlighting the value of carbon dioxide emission reduction. We have analyzed the rationale and principles of the contributions of the values of carbon assets, and have established the mathematical and simulation model of the evolution of carbon assets. Our simulation experiment results clearly demonstrate the emergent property of carbon assets. Various simulation circumstances can be set to obtain different scenarios of emergence in the evolution of carbon assets on the basis of the proposed model. Our study and associated output provide a solid foundation and practical framework for enterprises to analyze and manage carbon assets. 
Yin Zeng \& Shuliang Li, “ Agent-Based Simulation of the Evolution of Enterprise Carbon Assets”, Proceedings of 2016 International Conference on Robots \& Intelligent Systems, 27 ${ }^{\text {th }}$ 28th August 2016, Zhangjiajie, China. IEEE.pp.81-84. ISBN 978-1-5090-4155-8/16.

\section{REFERENCES}

[1] G. Marland, K. Fruit, R. Sedjo, "Accounting for Sequestered Carbon: the Question of Permanence", Environmental Science \& Policy, 2001, 4(6): 259-268.

[2] L. Yan, G. Huang, "Attributes and Pricing of Technology's Carbon Asset", Statistic Research, 2015, 32(2): 10-15.

[3] Y. Zhang, L. Wu, F. Su, "An Accounting Model for Forest Carbon Sinks in China", Journal of Beijing Forestry University, 2010, 32(2): 194-200.

[4] V. Bosetti, C. Carraro, M. Galeotti, "Stabilisation Targets, Technical Change and the Macroeconomic Costs of Climate Change Control", Feem Working Paper, 2006.

[5] J. Mukherjee, P. Tripathi, "Understanding the Drivers of Brand Loyalty in Mixed Media Context", Iims Journal of Management Science, 2016, 7(1): 1-13. 